\title{
ОЦЕНКА ПЕРСПЕКТИВ ВЗАИМНОЙ ТОРГОВЛИ СТРАН ЕАЭС С ИСПОЛЬЗОВАНИЕМ СЦЕНАРНОГО ПОДХОДА ${ }^{1}$
}

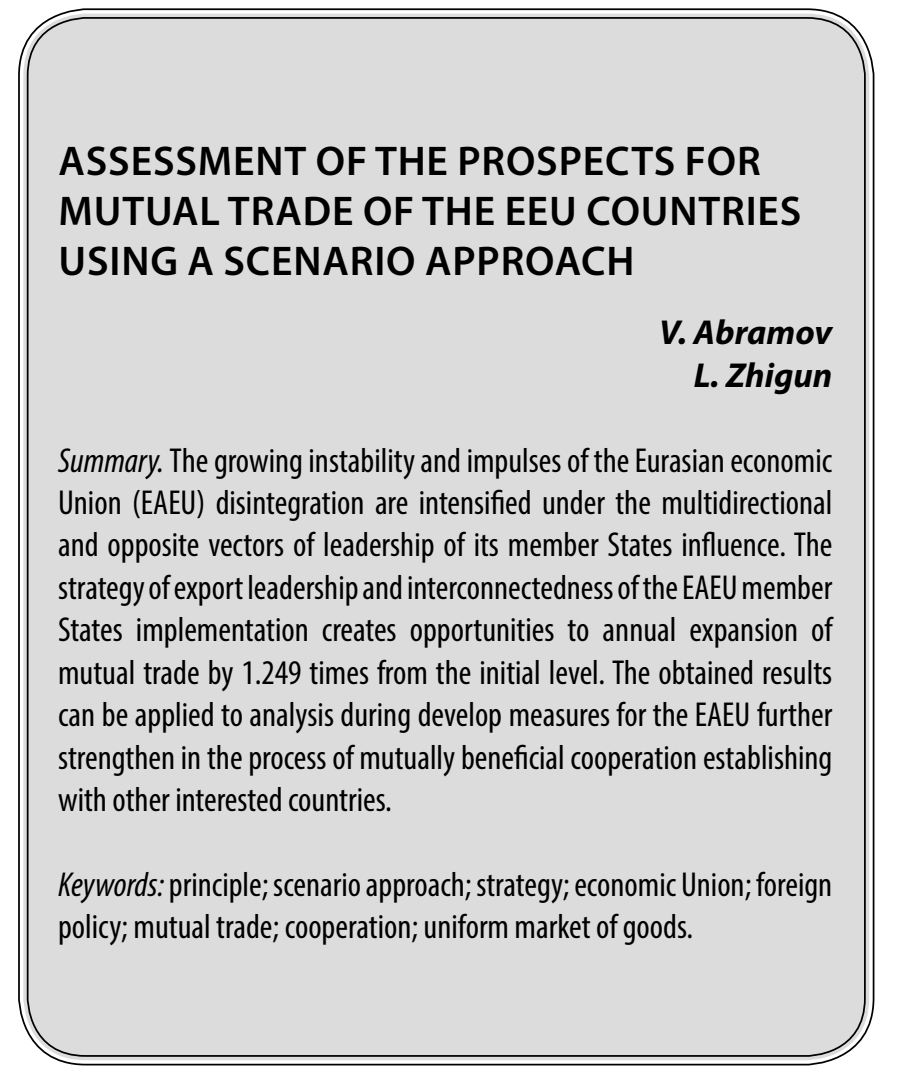

B конце второго десятилетия двухтысячных годов Россия уделяет особое внимание политике лидерства в международном имидже. Ее результаты ориентированы на защиту государства, граждан, общественных и государственных и частных экономических интересов в целях укрепления национальной экономики в условиях ухудшения отношений с США и Евросоюзом.

Научные публикации последних лет вносят весомый вклад в теоретические и практические аспекты развития экономической интеграции в различных регионах мира. Для интеграции, которая формируется группой стран вокруг страны - лидера, важную роль играют пороговые значения связанности национальных экономик, которая определяется долей взаимной торговли в общем объеме внешней торговли (Micbaely, 1996 [1]; Martin \&

\author{
Абрамов Валерий Леонидович \\ Д.э.н., професссор, г.н.С., Финансовый университет \\ при Правительстве $Р Ф$, Москва \\ valabr@yandex.ru \\ Жигун Леонид Александрович \\ Д.э.н., профессор, Российский экономический \\ университет \\ Им. Г. В. Плеханова, Москва \\ manpseu@yandex.ru
}

Аннотация. В условиях нарастания геополитической напряженности в функционировании Евразийского экономического союза (ЕАЭС) проявляются центростремительные и центробежные тенденции, что обусловливает актуальность исследуемой проблемы. Показано, что реализация сценария экспортного лидирования и взаимосвязанности государств-членов ЕАЭС создает потенциальные возможности для ежегодного расширения взаимной торговли в 1,249 раза от исходного уровня. Полученные результаты могут использоваться для анализа для разработки мер дальнейшего укрепления ЕАЭС в процессе установления взаимовыгодного сотрудничества с другими заинтересованными странами.

Ключевые слова: принцип; сценарный подход; лидерство; стратегия; экономический союз; взаимная торговля; сотрудничество; единый рынок товаров.

Tsangarides, 2006 [2]). Она в общем объеме торговли товарами стран ЕАЭС в 2014-2017 гг. составляла только медианное значение 13,5\%. Такой уровень значительно ниже минимального порога интеграционной устойчивости в $25 \%$, на что концентрируют внимание в своих статьях такие исследователи как Зевин Л. [3, с.19] и Абрамов B.[4, c. 5]).

В статье предлагается новый подход к исследованию экономической интеграции, в основе которого лежит сценарный подход для анализа последствий взаимной торговли стран Евразийского экономического союза.

Важным интеграционным эффектом для оценки политик государств- членов Союза применительно к дальнейшему развитию интеграционных процессов являются объемы их экспорта во взаимной торговле.

${ }^{1}$ Статья подготовлена по результатам исследований, выполненных за счет бюджетных средств по государственному заданию Финансового университета 2020 г. 
Таблица 1. Структура экспорта государствами-членами ЕАЭС во взаимной торговле в 2017 году, в \% от общего объема взаимной торговли.

\begin{tabular}{|c|c|c|c|c|c|}
\hline \multirow{2}{*}{ Экспортер / } & \multicolumn{5}{|c|}{ Доля экспорта,\% } \\
\hline & Армения & Беларусь & Казахстан & Кыргызстан & Россия \\
\hline Армения & 0 & 1,24 & 0,86 & 0,32 & 97,58 \\
\hline Беларусь & 0,25 & 0 & 4,34 & 0,9 & 94,5 \\
\hline Казахстан & 0,11 & 1,92 & 0 & 9,82 & 88,15 \\
\hline Кыргызстан & 0,02 & 1,31 & 49,6 & 0 & 49,07 \\
\hline Россия & 3,6 & 56,43 & 35,94 & 4,03 & 0 \\
\hline
\end{tabular}

Источник: О состоянии взаимной торговли между государствами - членами Евразийского экономического союза в 2018 году. Доклад. М.: Евразийская экономическая комиссия. 2018. - 94 с., расчеты авторов

Таблица 2. Сценарии лидирования стран ЕАЭС по росту экспорта во взаимной торговле на $10 \%$ от исходного уровня в 2017 году

\begin{tabular}{|c|c|c|c|c|c|}
\hline \multirow[t]{2}{*}{ Экспортер } & \multicolumn{5}{|c|}{$\begin{array}{l}\text { Результаты } \\
\text { сценарного роста }\end{array}$} \\
\hline & Армения & Беларусь & Казахстан & Кыргызстан & Россия \\
\hline Армения & 0 & 1,00124 & 1,00086 & 1,00032 & 1,09758 \\
\hline Беларусь & 1,00015 & 0 & 1,00424 & 1,0008 & 1,0944 \\
\hline Казахстан & 1,00011 & \begin{tabular}{|l|}
1,00192 \\
\end{tabular} & 0 & 1,00982 & 1,08815 \\
\hline Кыргызстан & 1,00002 & 1,00131 & 1,0496 & 0 & 1,04907 \\
\hline Россия & 1,0036 & 1,05643 & 1,03594 & 1,00403 & 0 \\
\hline $\begin{array}{l}\text { Индекс прироста } \\
\text { взаимного рынка }\end{array}$ & 1,00097 & 1,015225 & 1,02266 & 1,003743 & 1,0823 \\
\hline
\end{tabular}

Источник: расчеты авторов.

Согласно данным таблицы 1, Армения и Беларусь экспортируют свои товары преимущественно в Россию (97,58\% и 94,5\%), аналогичная ситуация характерна и для Казахстана, который имеет неоспоримое лидерство в экспорте своих товаров в Россию $(88,15 \%)$.

Кыргызстан почти в равной мере осуществляет экспорт своей продукции на два национальных рынка: Казахстана (49,6\%) и России (49,07\%). Россия экспортирует свою продукцию главным образом на рынок Беларуси $(56,43 \%)$ и на рынок Казахстана $(35,94 \%)$.

Выполненный анализ свидетельствует о том, что страны ЕАЭС не ориентированы на полномасштабную экономическую интеграцию, а преследуют возможность реализовать свои экспортные преимущества лишь в двух и реже в трехсторонних (Россия, Беларусь, Казахстан) взаимодействиях с государствами - членами. Отчасти такая ситуация обусловлена удаленностью стран, высоким уровнем логистических издержек, Другой немаловажной причиной является сложившаяся разнонаправленность векторов экспорта стран-членов ЕАЭС, которая препятствует укреплению интеграции единого рынка.
Выявить вклад стратегий экспортного лидирования каждой из стран в рост взаимной торговли позволяют сценарный подход во взаимосвязи с методом факторного анализа векторов [13]. Для этого данные таблицы 1 умножаются на единичный вектор, в котором последовательно оценивается вклад изменения пропорций экспорта в ЕАЭС при изменении экспорта анализируемой страны на 10\%, то есть коэффициент страны в единичном векторе принимается равным 1,1. Результаты сценарных расчетов представлены в таблице 2.

Исходя из данных таблицы 2 следует, что если Армения будет продолжать придерживаться действующей стратегии экспортного лидирования, то при сценарии увеличении ее экспорта на $10 \%$, ее воздействие станет сколько-нибудь заметным только лишь в торговле с Россией, где импорт из Армении вырастет на 0,36\% (1,0036×100-100), а на всем совместном рынке прирост рынка составит всего 0,097\% (1,00097×100-100).

При сценарном варианте сохранения действующей стратегии экспортного лидирования Беларуси, увеличение ею экспорта на 10\% более всего скажется на торговле с Россией, экспорт из нее увеличится на 5,64\% 
(1,05643×100-100). При этом вклад экспорта Беларуси в прирост единого евразийского рынка сможет дать уже $1,52 \%$.

Сценарный вариант увеличения экспорта Казахстаном на $10 \%$ в рамках его действующей стратегии экспортного лидирования вызовет максимальный эффект в торговле с Кыргызстаном $(4,96 \%)$ и ощутимый эффект в торговле с Россией (3,59\%). При этом варианте сценария, общая емкость рынка стран ЕАЭС под влиянием экспорта Казахстана может увеличится на 2,267\%.

Стратегия экспортного лидирования Кыргызстана малочувствительна для единого рынка стран ЕАЭС. Его влияние на единый рынок равно 0,37\% на каждые 10\% сценарного роста экспорта. Более всего к ней чувствителен только Казахстан (0,98\%).

Максимальное влияние сценарного роста на единый рынок оказывает стратегия экспортного лидирования России (8,23\%). Она положительно сказывается на генерации динамики роста экспорта в Армению $(9,76 \%)$, Беларусь $(9,44 \%)$ и в Казахстан (8,81\%).

Сценарный анализ показывает, что в целом, несмотря на некоторую ограниченность стратегий экспортного лидирования стран ЕАЭС, объем взаимной торговли государств-членов получает значительный интеграционный эффект: на каждые 10\% сценарного роста экспорта каждого из государств емкость рынка увеличивается на 12,49\%. Такое значение роста рынка хорошо согласуется с критерием устойчивости интеграционных институтов, сформулированными исследователями [4]. На современном этапе ключевыми проблемами интеграции, увеличения объемов взаимной торговли в рамках ЕАЭС являются: «основная сырьевая направленность экономики стран-участниц (Россия, Казахстан); преобладание национальных интересов над интересами Союза; наличие обширной территории, большого количества населения; нарастание авторитета России среди союзников; различие темпов экономического роста стран-участниц ЕАЭС» [14]. Следовательно, получаемый интеграционный эффект характеризует не только наличие взаимной экономической выгоды у государств-членов ЕАЭС, но и достаточную для дальнейшего развития устойчивость совместного рынка.

\section{Выво $\triangle$}

Анализ стратегий экспортного лидирования стран ЕАЭС на едином евразийском рынке выявил, что они направлены на достижение экспортных преимуществ лишь в двух и реже в трехсторонних взаимодействиях. Показано, что реализация сценарных стратегий экспортного лидирования и взаимосвязанности стран ЕАЭС создает возможности ежегодного расширения объемов взаимной торговли в 1,249 раза от исходного уровня. А это в свою очередь, обеспечивает функционирование единого рынка товаров на уровне минимального порога интеграционной устойчивости. При этом единый рынок ЕАЭС получает значительный синергетический эффект, способствующий его укреплению и динамичному развитию, что обеспечивает экономическую выгоду его участникам. Полученные результаты могут использоваться для анализа других интеграционных объединений, а также для дальнейшего укрепления ЕАЭС в процессе установления взаимовыгодного сотрудничества с другими заинтересованными странами.

\section{ЛИТЕРАТУРА}

1. Micbaely M. Trade Preferential Agreements in Latin America: An-Ante Assesment. World Bank Policy Research Working Paper No. 1583. World Bank. 1996.60 p.

2. Martin J.K., Tsangarides C. Trade Reform in the CEMAK: Developments and Opportunities // IMF Country Report No. 06/309. Washington D. C.: IMF. 2006. 20 p.

3. Зевин Л. З. 0 некоторых проблемах экономического пространства Евразии XXI века. Москва.: Институт экономики ИЭ РАН. - 40 c.

4. Абрамов В. Л. Экономическая устойчивость национальных экономик государств - членов ЕАЭС как фактор формирования конкурентных преимуществ: теория и практика // Современная наука: актуальные проблемы теории и практики. Серия «Экономика и право»,_ 2017. - № 10.— С. 3-8.

5. Жигун Л. А. Методологические проблемы определения добавленной стоимости в международной торговле // Вестник Российской таможенной академии. - 2015.—№ 3.—C. 123-129.

6. Mussataev S., Mekebaeva M. Political-economic problems of integration within Eurasian economic union. Bulletin Abay Kazakh National Pedagogical University. Almaty. 2016. - p. 1-5.

( ) Абрамов Валерий Леонидович ( valabr@yandex.ru ), Жигун Леонид Александрович ( manpseu@yandex.ru ). Журнал «Современная наука: актуальные проблемы теории и практики» 